\title{
Constant ratio
}

\section{This apparatus, held in London's Science Museum, has some significant purpose - or curiosity value - in the history of physics. Can you guess what it is?}

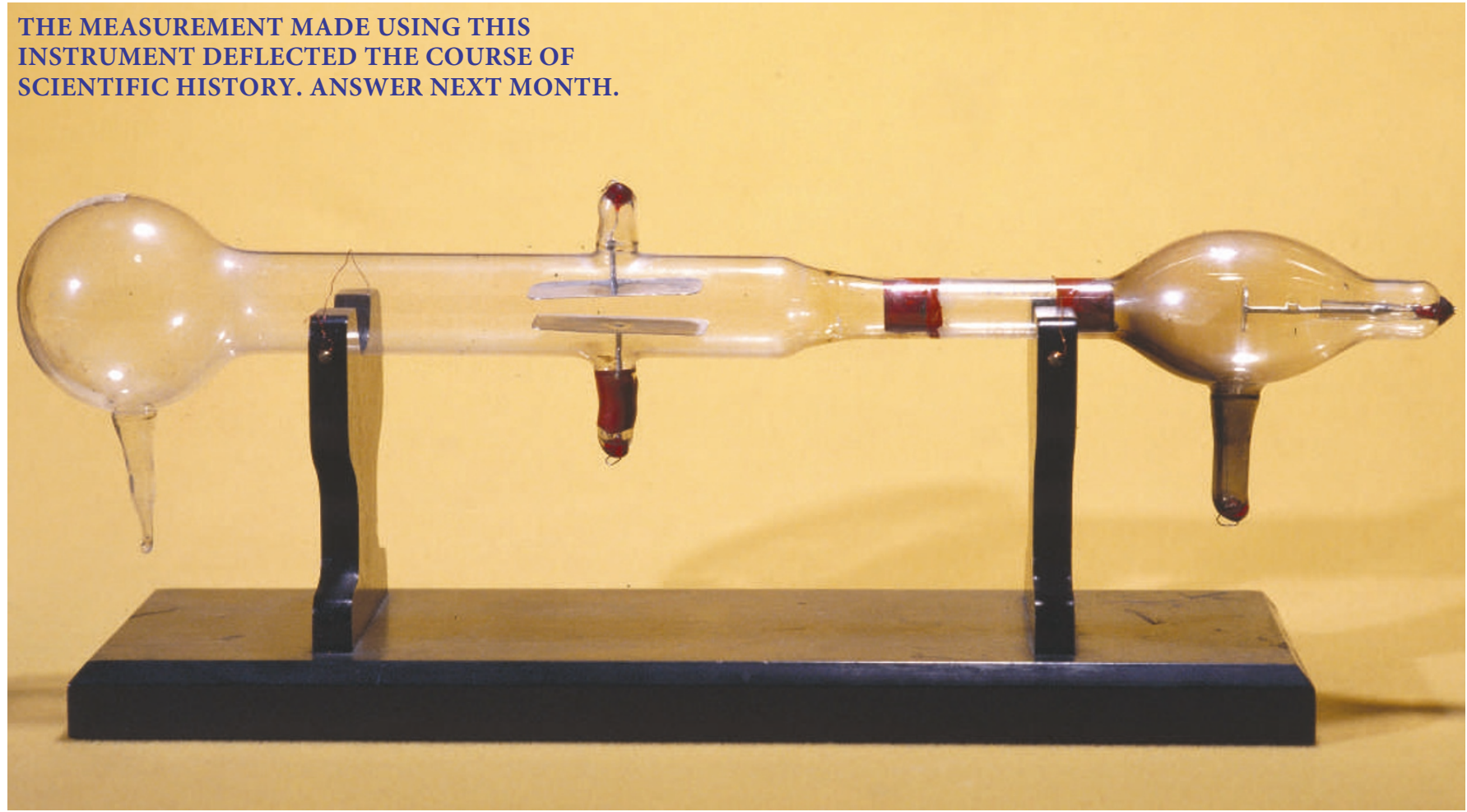

Joseph Priestley was a dissenting minister, chemist and natural philosopher, a man of very wide interests. He was a member of Birmingham's Lunar Society - a group of friends, including engineer James Watt and pottery manufacturer Josiah Wedgewood (grandfather of Charles Darwin), who met under the full moon to discuss scientific issues. One of his enthusiasms was electricity. In 1767 , he wrote the first history of the subject, in which he gave a critical account of electrical machines up to that time, comparing his own design favourably.

This electrical machine, which required only one person to operate it, was probably made by Priestley in around 1768. It uses a glass globe rather than the more usual cylinder, because globes could be blown more

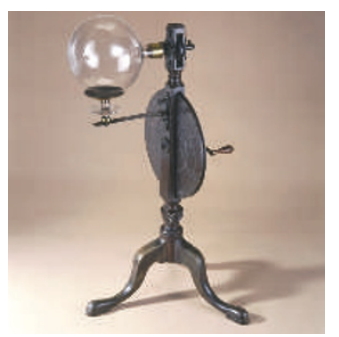

Last month: Priestley's electrical machine

science museum easily. Globes of different sizes could be placed on the machine, and it could generate both positive and negative electricity.

Originally it had a prime conductor in the form of a comb, wire and onion-shaped brass vessel. The amount of charge accumulated could be read from a Lane's electrometer, a device that measured the length of sparks. When the machine was set up to produce negative electricity, the prime conductor was earthed using a chain and the charge was taken from the rubber rather than from the globe itself.

Electricity had become a popular topic for lecturers in experimental philosophy after 1745 , when it was discovered that it was possible to store charge in a glass bottle, called a Leiden jar. Spectacular demonstrations of people being electrified - usually children or servants - were performed for ladies and gentlemen.

Priestley's interests were in discovering the properties of the 'electric fluid', a surfeit or absence of which was thought to cause positive or negative electricity. He experimented on what was later known as a Faraday cage - the absence of charge inside a highly charged conductor - and speculated that electric force obeyed the inverse square law, like gravity.

\section{JANE WESS}

Jane Wess is a curator at the Science Museum, Exhibition Road, South Kensington, London SW7 2DD, UK.

www.sciencemuseum.org.uk 